\title{
Perceptions of Chinese and Tanzanian employees regarding intercultural collaboration
}

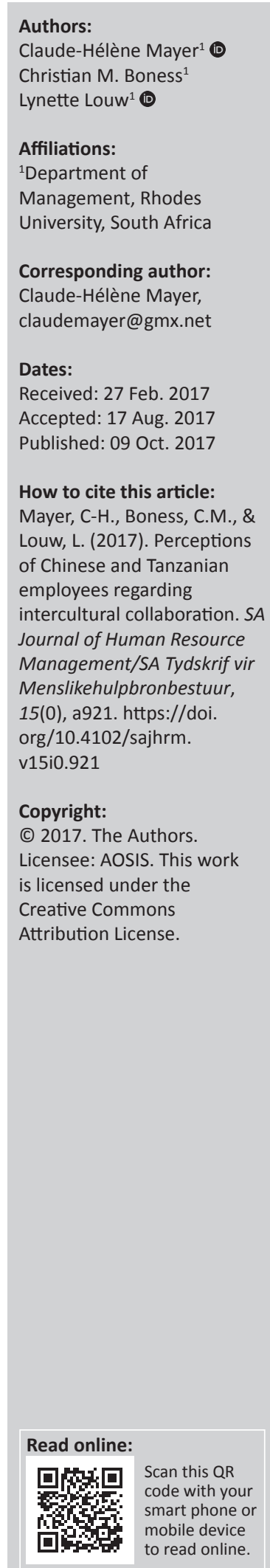

Orientation: Chinese organisations have a long tradition of operating in Tanzania, and even today, Tanzania is the gateway for Chinese interests entering sub-Saharan markets.

Research purpose: The purpose of this article was to explore and understand the perceptions of Chinese and Tanzanian employees working in a private Chinese organisation in Tanzania.

Motivation for the study: The authors would like to contribute to the discourse on Chinese and Tanzanian collaboration in southern Africa to improve context-based intercultural collaboration from a human resource management perspective.

Research design, approach and method: The study used a case study approach within a hermeneutical research paradigm. Data were collected through semi-structured interviews and observation in a selected private Chinese organisation. Data were analysed by content analysis using Terre Blanche's five-step model of content analysis.

Main findings: The findings show that intercultural collaboration is a challenge for both Chinese and Tanzanian employees. Chinese employees share a mostly positive view of their organisation, while Tanzanians tend to be more critical. Members of both groups, however, feel that intercultural collaboration could improve if members of 'the other group' made recommended changes. Despite this, both groups adhere to their perceptions of 'the other' and maintain a favourable view of the self.

Practical/managerial implications: Chinese organisations need to create opportunities for the improvement of intercultural collaboration by reflecting on the self and 'the other' in terms of understanding thought styles, experiences, knowledge, and the impact of cultural values on collaboration behaviour. As such, cultural knowledge-sharing might contribute to a sustainable long-term intercultural collaboration.

Contribution: The study contributes to filling the gap of in-depth qualitative research on perceptions of Chinese and Tanzanian intercultural collaboration between employees in the field of human resource management in Africa.

\section{Introduction}

China's impact and role in the development of countries in Africa, primarily through foreign direct investments and grants to governments, has increased in the past decade. For instance, the total value of trade between China and Africa was USD198.5 billion in 2012, increasing to USD385bn in 2015 (African Economic Outlook, 2014, p. 76).

A growing number of Chinese private and governmental organisations are investing in southern Africa. In Tanzanian contexts, this leads to a close collaboration of Chinese and Tanzanian employees (African Economic Outlook, 2014). These collaborations in Chinese organisations in Tanzania lead to intercultural communication situations and to new intercultural experiences and perceptions.

As a result of globalisation, intercultural collaboration has become extremely prevalent during the past decades and research has emphasised that employees in intercultural work situations are often challenged by intercultural collaboration (Hinds, Liu \& Lyon, 2011). It has been highlighted that the potential for conflict increases in intercultural work situations (Mayer \& Boness, 2011; Mayer \& Louw, 2012) and that having a dynamic and contextualised view of culture can support an improved understanding of the perceptions in intercultural collaboration (Hinds et al., 2011). Culture, in this case, is viewed as a group phenomenon which is defined primarily by values, norms and basic assumptions (Rosinski, 2011) and which impacts strongly on the collaboration between members of different cultural groups (Mayer, 2011). The latest 
research has shown that values differ recognisably across Chinese and sub-Saharan African cultures (Matondo, 2012), and it can be assumed that these value differences create differences in perception and challenges in intercultural collaboration.

\section{Purpose}

With little systematic empirical research and information currently available, a research void exists regarding Chinese-Tanzanian employee collaboration and employees' perceptions of this intercultural collaboration. This article aims to contribute to filling this void through qualitative in-depth research and by exploring perceptions of Chinese and Tanzanian employees working in a private Chinese information technology (IT) organisation in Dar-esSalaam, Tanzania.

The principal aim of this research study is to explore and understand the mutual perceptions of Chinese and Tanzanian employees in intercultural collaboration in a selected Chinese organisation in Tanzania. The main research question based on this primary aim is therefore: 'How do Chinese and Tanzanian employees perceive their intercultural collaboration in a private Chinese IT organisation?'

\section{Literature review}

\section{Contextual insights into Chinese-Tanzanian collaboration}

'Africa needs a market for its products. Africa needs technology for its development. China is ready to provide all that. What is wrong with that?' (Majani, 2013, n.p.) As this quotation suggests, the relationship between China and Africa - in this case, Tanzania - is a contentious issue.

Tanzania is looking back at a long intercultural history of Chinese business and close intercultural collaboration of Chinese and Tanzanian traders and entrepreneurs reaching back to the 15th century. The first contacts between Tanzanian and Chinese people occurred approximately 100 years before the first Europeans reached the region (Curtis, 2015).

The beginning of the modern era of Chinese contributions to the region started in the 1970s with the railway having been built from 1970 to 1975 (Tanzanian-Zambia Railway Authority, 2017). According to Bräutigam (2009, p. 40), Chinese workers built the longest railway in Africa stretching from the harbour of Dar-es-Salaam to the copper mine fields of Zambia. After China awoke from its cultural revolution, it engaged into a south-south trade with African countries. China's interest was based on its idea that China itself was a developing country with a similar structure to the majority of African countries, and Chinese investors felt that they knew how to operate in African countries (Bräutigam, 2009). In Tanzania, characteristics of Chinese aid and trade became visible in the 1980s:

In Tanzania the Chinese signed an agreement to renovate more than sixty former aid projects. Hydropower stations built earlier under Chinese aid ... received complete overhauls. Chinese officials complained mildly that it was more complicated than new construction, but they persisted. Being responsible to the end became a new slogan for aid. (Bräutigam, 2009, p. 57)

Apart from this new slogan, the Chinese strategy also included the principle of not interfering in internal affairs, but helping countries to build self-reliance (Bräutigam, 2009, p. 57).

\section{Managing Chinese organisations in African countries through intercultural collaboration}

Numerous research studies have focused on intercultural collaboration as well as on intercultural conflict management and negotiation in intercultural and international management cooperation (De Klerk \& Kroon, 2007; Harris, Brewster \& Sparrow, 2006; Hinds et al., 2011; Pillay, 2008; Sycara, Gelfand \& Abbe, 2013). Management research in African countries and Tanzania has evolved during the past decades, focusing on challenges of intercultural collaboration (George, Khayesi \& Haas, 2016; Kamoche, 2002; Kamoche, Debra, Horwitz \& Muuka, 2004; Mayer, 2008, 2011). This is also true for Chinese management contexts, highlighting that Chinese organisations have recognised the importance of an interculturally competent workforce within the global economy. However, the intercultural collaboration competence of employees still needs to improve to work sustainably in international collaboration (Koehn, 2007).

Managing people in African countries requires a multifaceted knowledge of historical, socio-economic and political complexities (Jackson, 2004; Luiz, 2006). It also needs to take cultural and work values, motivation, communication and human interaction into account (King, Kruger \& Pretorius, 2007). Cultural management philosophies such as Ubuntu (Luchien \& Honorine, 2005) and organisational change need to be addressed (Hart, 2002).

Globalisation, socio-economic and political changes within sub-Saharan Africa have led to an increase in intercultural collaboration, international business collaboration, communication and conflict management (Van der Nest, 2004). Often, management in Africa has been perceived (at least from an outside and intercultural perspective) as a challenge with high conflict potential resulting from the administrative organisation, political instability, personal security, lack of business confidence, transparency and difficult labour relations (Humphreys \& Bates, 2005).

This article focuses primarily on the exploration of perceptions on intercultural collaboration between Chinese and Tanzanian employees. In the past, intercultural collaboration has 'often been achieved through the domination of one culture by the other' (Graen, Hui \& Gu, 2004, p. 225), however, this approach has been proven to be dysfunctional and inadequate. Successful, effective and long-term intercultural collaboration needs to take into account the perceptions of the collaboration of the people themselves, and it needs to take the system-level approach in terms of organisational structures into account (Graen et al., 2004). Cultural aspects also need to be considered to develop 
effective intercultural collaboration (Trompenaars \& Asser, 2010) and to understand how individuals think, behave and form their attitudes (Mayer, 2008; Zait \& Spalanzani, 2009).

The perceptions of Chinese and Tanzanian employees working in Chinese organisations in Tanzanian contexts have hardly been considered in the context of intercultural collaboration (Mayer, 2013). Recently, research in different African countries has emphasised that in Africa-China joint ventures across 12 African countries, African partners use informal, even 'clandestine' mechanisms to manage cultural differences in order to gain knowledge (Ado, Su \& Wanjiru, 2016), while other research sees a huge potential in bridging cultural differences through the philosophies of Ubuntu and Confucius (Nyambegera, Kamoche \& Siebers, 2016). These authors emphasise major challenges in Chinese-African collaboration with regard to work attitudes, trust, the importance of work and what aspects of work employees place value on. Chinese enterprises have been criticised for their exploitative and abusive human resource management practices. However, it seems that cultural differences with regard to recruitment, relationship-building, authority, sanctions and incentives, reciprocity, social roles and symbolic significances seem frequently ignored (Giese, 2013). Qualitative research is needed to explore the cultural differences in-depth. Intercultural misunderstandings, which guide individual attitudes and behaviour, can cause international business failures and insensitivities in Chinese human resource management when addressing issues such as hiring, promotion, reward systems and dismissal in African contexts (Nyambegera et al., 2016). In an attempt to address some of these misunderstandings, the research at hand explores perceptions of Chinese and Tanzanian employees in a specific Chinese-African context.

\section{Method}

\section{Research approach}

This study uses a phenomenological (hermeneutic) research approach (Gummesson, 2000) while adopting an explorative and descriptive research methodology by using a social constructivist perspective (Collis \& Hussey, 2003).

\section{Research strategy}

This research project focuses on a large-scale organisation operating internationally as a private Chinese organisation. It is based on the sector of IT, and its products are telecommunications equipment and networking equipment. The ownership is completely Chinese. The organisation employed approximately 160 people in the Tanzanian branch at the time this research was undertaken.

For this study, convenience and snowball sampling in the organisation was used. Altogether 16 interviewees were willing to participate voluntarily in the research project. Of these, 6 were women and 10 were men; 6 were Chinese, 9 were Tanzanian and 1 person was Zambian. Two interviewees had worked less than 1 year in the organisation, while the remaining interviewees had worked there for more than 1 year.

\section{Research design}

Data were collected by conducting semi-structured interviews and by observations made. The semi-structured interviews were conducted face-to-face and ranged from $30 \mathrm{~mm}$ to $90 \mathrm{~min}$ in length. The interviews were conducted in English, Kiswahili or Chinese (Mandarin), according to the language abilities of the interviewees. The research team consisted of one Tanzanian, one Chinese-Tanzanian and two German researchers who were able to conduct the interviews in the three languages without using external translators. All of the researchers were familiar with the Tanzanian cultural environment. The interview questions focused on the organisation, its contextual environment and organisational culture, as well as on the collaboration between Chinese and Tanzanian employees within the organisation. The notes from the observations were used to interpret the statements in the interviews.

The semi-structured interview questions were developed following an extensive literature review. Some examples of the questions are as follows:

- Please talk about your perceptions of collaboration with regard to intercultural work collaboration between Chinese and Tanzanian employees.

- How do you experience the collaboration between Chinese and Tanzanian employees within the organisation?

- What do you enjoy about working for the organisation?

- What do you experiences as challenging in the collaboration and within the organisation?

Data were transcribed verbatim and were stored according to the ethical guidelines. The data were also transferred back to the participating organisation and employees.

The analysis was based on the five-step process of content analysis described by Terre Blanche, Durrheim and Kelly (2006, pp. 322-326). The five steps of content analysis used in the data analysis process were: familiarisation and immersion, inducing themes, coding, elaboration, and finally interpretation and checking. Data generated from observation contributed to the interpretation of information and are implicitly included in the findings and interpretation of the research. Inter-validation processes among the research team members were also used (Yin, 2009, p. 45).

Qualitative research criteria (Gummesson, 2000, p. 157) were applied in the study, namely credibility, transferability, trustworthiness and confirmability (Mayer, 2011). The transparent description of this research leads to credibility, as well as to the transferability and trustworthiness of the research (Creswell, 2003).

\section{Findings}

The biographical information shows the characteristics of the interviewees in terms of their position in the organisation, their nationality and mother tongue, their age, sex and duration of work time in the organisation (Table 1). 
TABLE 1: Biographical data.

\begin{tabular}{|c|c|c|c|c|c|}
\hline Code number & Position & Nationality, mother tongue & Age in years & Sex & Tenure in organisation/months \\
\hline $1 \mathrm{~h}-\mathrm{m}$ & Deputy managing director & $\mathrm{Rc} / \mathrm{Ch}$ & 35 & M & 36 \\
\hline $2 \mathrm{~h}-\mathrm{m}$ & Product manager & $\mathrm{Rc} / \mathrm{Ch}$ & 40 & M & 12 \\
\hline $3 \mathrm{~h}-\mathrm{m}$ & HR manager & $\mathrm{z} / \mathrm{Su}$ & 35 & $\mathrm{~F}$ & 7 \\
\hline $4 \mathrm{~h}-\mathrm{m}$ & Channel executive & $\mathrm{Tz} / \mathrm{Su}$ & 40 & M & 96 \\
\hline $5 \mathrm{~h}-\mathrm{e}$ & CSO department employee & $\mathrm{Tz} / \mathrm{Su}$ & 30 & $\mathrm{~F}$ & 60 \\
\hline $6 \mathrm{~h}-\mathrm{e}$ & Pre-sales engineer & $\mathrm{Rc} / \mathrm{Ch}$ & 35 & M & 4 \\
\hline $7 \mathrm{~h}-\mathrm{e}$ & Project manager & $\mathrm{Tz} / \mathrm{Su}$ & 40 & M & 24 \\
\hline $8 \mathrm{~h}-\mathrm{e}$ & Officer & $\mathrm{Tz} / \mathrm{Su}$ & 30 & $\mathrm{~F}$ & 12 \\
\hline $9 \mathrm{~h}-\mathrm{e}$ & Administration & $\mathrm{Tz} / \mathrm{Su}$ & 30 & $\mathrm{~F}$ & 48 \\
\hline $10 \mathrm{~h}-\mathrm{m}$ & Product manager & $\mathrm{Rc} / \mathrm{Ch}$ & 35 & M & 24 \\
\hline $11 \mathrm{~h}-\mathrm{m}$ & Public relations manager & $\mathrm{Rc} / \mathrm{Ch}$ & 40 & M & 36 \\
\hline $12 \mathrm{~h}-\mathrm{m}$ & Director of finance & $\mathrm{Rc} / \mathrm{Ch}$ & 40 & M & 16 \\
\hline $13 \mathrm{~h}-\mathrm{e}$ & Health and safety agency manager & $\mathrm{Tz} / \mathrm{Su}$ & 30 & $\mathrm{~F}$ & 60 \\
\hline $14 \mathrm{~h}-\mathrm{m}$ & Network solution designer & $\mathrm{Tz} / \mathrm{Su}$ & 35 & M & 24 \\
\hline $16 \mathrm{~h}-\mathrm{e}$ & Administrative assistant & $\mathrm{Tz} / \mathrm{Su}$ & 30 & $\mathrm{~F}$ & 11 \\
\hline
\end{tabular}

Source: Mayer, C.-H., Boness, C.M., Louw, L. \& Louw, M.J. (2016). Intra- and inter-group perceptions of Chinese and Tanzanian employees in intercultural cooperation. Proceedings of the 28th Annual Conference of the Southern African Institute of Management Scientists, p. 123. Retrieved August 24, 2017, from http://www.up.ac.za/media/shared/643/ZP Files/2016/Papers/hrl18 full.zp97856.pdf Rc, Republic of China; Ch, Chinese language; Tz, United Republic of Tanzania; Su, Swahili language; Z, Zambia; M, male; F, female.

The following section presents the findings regarding various perceptions of Tanzanian and Chinese employee collaboration.

\section{Perceptions of Tanzanian and Chinese employees in intercultural work encounters}

It was found that, when asking Chinese and Tanzanian employees about their perceptions of intercultural collaboration, the following themes arose:

- strategy

- $\quad$ structure and decision-making

- management styles

- employment

- qualification and training

- knowledge-sharing

- motivation and incentives

- working conditions and atmosphere

- environment community, government and trade unions.

\section{The perceptions of Tanzanian employees}

\section{Strategy}

A Tanzanian employee (14 h-m) provides a short explanation of the organisation's strategy:

The long-term strategy I can say is to be the best ICT solution provider in the country. That is how I can summarise it. (Participant 14, Network Solution Designer, Tanzanian male, 35 years)

For the Tanzanian interviewees, the main strategic goal is clear: to become number one in the field of IT. However, most of the Tanzanian interviewees were unclear about the strategic outline of the organisation. They feel that their job descriptions are vague and that they are not included in the organisation's strategic planning.

\section{Structure and decision-making}

A Tanzanian employee (5 h-e) spoke about decisions in the organisation and how they are handled:
Sometimes they do inform us, but sometimes they just pass the decision on. You just find out that decisions are already made, so I just have to obey. (Participant 5, CSO department employee, Tanzanian female, 30 years)

Tanzanian employees believe that, in this organisation, the bosses are 'at the top' and supervisors take care of employees at different levels; this portrays a rigid organisational structure. Tanzanian employees do not participate in decisionmaking. The Tanzanian employee quoted above found that decisions are most often taken without being communicated. Employees do not participate in decision-making and must obey. Other Tanzanian employees emphasised that there are no open discussions about decisions among the employees. They even think that employees are not consulted on any decision-making issues. However, Chinese management seems to follow an increasingly localised focus which they believe will improve their international operations as they grow more accustomed to their external working environment.

\section{Management styles}

A Tanzanian employee (16 h-e) working on lower management level states:

If a Chinese comes to you, and ask for something and you tell that person then I'm not supposed to give you this ... because you have to get an approval from my supervisor if you can get this thing or this item that you want. There are some stuff that you just don't give away. You have to get an approval first and then he or she shouts at you or like, 'who do you think you are?' 'Who do you think you are in this organisation?' Something like that ... Yah! It happens. (Participant 16, Administrative assistant, Tanzanian female, 30 years)

This Tanzanian employee mainly perceives the Chinese as working according to formal bureaucratic rules, which are not transparent to her. She perceives a communication style of shouting and offensive behaviour, which she does not appreciate. Other Tanzanian employees see top management as being strongly focused on results rather than being people- 
orientated. It is also believed that the management style combines Chinese and Western values and that these styles are interlinked. Although it is perceived that the organisation has a very autocratic management style with the main focus on work, Tanzanian employees experience some support from the organisation to its staff members, although somewhat less than desired.

\section{Employment}

The impression of this Tanzanian employee (7 h-e) shows a changing ratio between Chinese and Tanzanian employees:

From their side they'll take advantage of, maybe bring in some more maybe whether Chinese whatever they, they bring that, to cover that position. But in, in fact it doesn't mean that we are not capable of doing that. Even sometimes even within the position we are, we are just performing like we are, we are, we are letting days to be numbered while we are looking for some better, maybe ways. (Participant 7, Project managers, Tanzanian male, 35 years)

The interviewee seems to be disappointed that positions which could be filled by Tanzanians are occupied by the Chinese workforce. Several Tanzanian employees believe that there is an unequal distribution of workers in terms of cultural origin. There is a ratio of approximately 60 Chinese to 40 Tanzanians employed in the organisation. Tanzanians expect the ratio to be equalised.

A Tanzanian employee (15 h-m) perceived the employment policy of the Chinese HR management as disempowering Tanzanians:

You know they are not employing, they are not employing. For example, this year, last year I didn't see any person but what they do, if for example local staff leave the organisation they just bring Chinese and you just see Chinese coming, that you understand. So, they are not employing. (Participant 15, Spare parts managers, Tanzanian male, 35 years)

This employee argued against the objective figures of employment in the organisation. He only sees Chinese coming to fill the positions which he might have assumed were to be filled by Tanzanian workers. Obviously, a high fluctuation of employees is also observed by other Tanzanian employees. This constant movement results in less room for interpersonal relations, leading to the opinion that HR policies are not clear. Additionally, Chinese 'foreigners' are given more learning opportunities than Tanzanians.

\section{Qualification and training}

A Tanzanian employee (13 h-e) offered quite a positive statement about the issue of qualification and training:

... most of them is online training. Yes we have online training and before I came here I had training and then after I trained I had an exam and then after the exam you get a score, yes it is something like that we have. (Participant 13, Health and safety agent manager, Tanzanian female, 30 years)

While the organisation has a good training system in which employees are trained to deal with new technologies, it addresses qualification gaps by providing on-the-job training. However, the majority of Tanzanian employees judge the level of qualification in the organisation as low. Employees are not well trained and lack basic knowledge. Tanzanian employees feel that the online training platform is helpful, but that the online training, skills and the expertise gained are limited. As a result, the organisation prefers to employ Chinese employees at top-level management who are, according to Chinese perception, more skilled than Tanzanian employees.

\section{Knowledge-sharing}

In terms of knowledge-sharing, a Tanzanian employee (15 h-m) commented:

Support is there, but not one hundred per cent ... You know here in 'Go Away' we have learnt many things. You can be given a job, someone can come and tell you: 'do this' but I have never done it. I tell him, 'I don't know; no just learn from others, ask your friends'. My supervisors don't have time to teach me and they say 'here nobody can teach you, you have to teach yourself. If you don't know then find the one who can'. So we found that we don't have much support from Chinese. (Participant 15, Spare parts managers, Tanzanian male, 35 years)

Tanzanian employees experience a lack of knowledgesharing within the organisation. Tanzanian interviewees find that the Chinese seem to segregate themselves and do not particularly interact with Tanzanian employees, causing an information barrier and less transparency. Because there are no new employment or career opportunities available, this tends to put a limit on knowledge-sharing as there is hardly any motivation to share knowledge. Supervisors do not teach employees, and the employees end up seeking knowledge from external sources around the country and beyond.

\section{Motivation and incentives}

Regarding the system of rewards, a Tanzanian employee (3 h-m) stated:

We also have incentives like if you are working on a particular project and you deliver it successfully you are given an incentive for working on that project and that is like as and when the project matures; whereas with the bonuses and annual thing the incentive award comes out when the project matures. Yeah so there is all of those freebies or all of those goodies that are thrown into the whole compensation and benefit package that tend to be quite attractive. So with those incentives I think people are driven to work harder because they know if I deliver on X I am going to get said; so it is pure and simple. (Participant 3, HR managers, Zambian female, 35 years)

This Tanzanian employee finds the reward system attractive, because it could encourage the workers to work harder. However, the opinions of Tanzanians on this topic vary greatly. Regarding rewards and benefits, some Tanzanians think that rewards should be available equally to all employees. There is induction training which is useful in that employees are trained timeously with new technologies. Education and numerous training platforms exist, from onthe-job (face-to-face) training to online training. 
Other Tanzanians stated that the reward system in this organisation is performance-based, where the employer and employee agree on certain targets to be met within a given time frame. Reviews are then done at the end of that period, after which bonuses and remuneration elements are worked out. The Tanzanian view is that, although this may be productive for the organisation, it also may be used as a 'trick' to control wages. Tanzanians prefer a fixed salary for permanent workers, with a bonus-related scheme for exceptional work performance.

\section{Working conditions and atmosphere}

A Tanzanian employee ( $5 \mathrm{~h}-\mathrm{m})$ noted that the working conditions are often affected by the language barriers:

You need to be patient because Chinese people, they panic. It is because sometimes, they have to understand English, and they understand Chinese only. So if you are speaking and they don't know what you are speaking about, just be patient. [laughter]. (Participant 5, CSO department employee, Tanzanian female, 30 years)

In addition to language problems which may affect communication fundamentally, other difficult aspects of the work environment were also mentioned by Tanzanian employees. Some Tanzanians place particularly high value on interpersonal relations. However, the atmosphere in this private Chinese organisation allows very little room for interpersonal relations; Chinese employees seem to be more work-orientated and less relations-based. In the organisation, it is evident that there is a general norm of Chinese employees to display in-group behaviour and have less personal interaction with local employees. Tanzanians attribute this to the high mobility and turnover rates of Chinese employees, preventing the establishment of strong relationships.

Language barriers with regard to documents are also perceived as impeding the development of sound interpersonal relations. As a Tanzanian employee (16 h-m) observed:

\footnotetext{
... we all understand each other. But sometimes (sigh) sometimes you might be given a document to sign, which is written in Chinese. So, you don't know what is there but you're just told, 'Sign!' (Participant 16, Administrative assistant, Tanzanian female, 30 years)
}

Some Tanzanian employees believe that there is an overemphasis on work as the Chinese employees often 'overwork'. Chinese tend to expect more from Tanzanians than the average job description entails. Tanzanians are aware of high cultural barriers that exist between the cultures. Thus, integration within the organisation becomes difficult and requires a great deal of effort. It is observed that supervisors do not teach local Tanzanian employees and the employees often end up seeking knowledge from external sources around the country and beyond. This results in a counterproductive work environment, which is characterised by a lack of information transparency.

\section{Environment community, government and trade unions}

A Tanzanian employee ( $5 \mathrm{~h}$-e) was convinced of the benefits of hardworking Chinese employees in Africa:

They are very hardworking people. When they mean to do something, finish something, they mean it. They work day and night sometimes just to make sure that thing is done. Or if there are other projects we need to win, they really work hard. They make Africa go up in terms of technology issues. We are going high in technology because of them. (Participant 5, CSO department employee, Tanzanian female, 30 years)

This Tanzanian employee sees his Chinese counterparts as highly competitive in their working ethics and behaviour. With this in mind, Africa as a continent would benefit technologically from Chinese-Tanzanian collaboration.

Other Tanzanian employees appreciate the supporting of schools and various projects and initiatives in the community by the Chinese. The Chinese also interact with the local businesses as they purchase goods and services from other local firms. The presence of the Chinese is seen as beneficial to the community, as evidenced in the increase in employment opportunities for local businesses. Tanzanians also feel that the Chinese play an important role in helping local entrepreneurs gain more experience in their field of work.

\section{The perceptions of Chinese employees}

\section{Strategy}

A Chinese employee (1 h-m) underlined the organisation's strategy with following words:

So our mission is wanting to enrich the communication between the people we want to, how do you say, to reduce the gap between the people especially for Africa. I am talking about our mission in Africa obvious especially for our developers in Europe and America; they have already finished the job but for Africa we want to bring the good solution with a reasonable price to the people here. (Participant 1, Deputy managing director, Chinese male, 35 years)

This leading Chinese employee obviously saw the organisation's strategy as pan-African: enriching communication between people at a reasonable price. The majority of Chinese employees understood the organisation's strategy as forming connectivity and solid relationships in Africa. The main focus in the organisation, as highlighted by Chinese employees, was on achieving a high level of teamwork, efficiency and a sense of responsibility. Support is provided to everyone, and avoidance of risk is emphasised. Chinese employees believed that through the implementation of this strategy, the organisation could become a key driver in the industry, as well as being able to introduce the best IT solutions to the customer.

\section{Structure and decision-making}

The structure of the organisation was described by a Chinese top manager (12 h-m): 
Yes, in this organisation we have the MD, Managing Director and we have Director of Finance, me, and Director and technical delivery and there is directors for key accounts and we have the main customers system like Airtel and ... it's the business directors, one MD and me Finance Director and Technical and Service and Delivery Director and four directors for each different business and we all report to the MD all of us. I think when we have a business we have marketing strategy and we have our principles and some projects for maybe senior level should obey our mother organisation from China and the MD has a certain level of authority a certain amount but the amount is bigger to high levels and regional and headquarters. (Participant 12, Director of finance, Chinese male, 16 years)

The interviewee explained the strict hierarchies regarding reporting structures to the Chinese headquarters. Regarding decision-making and participation, other Chinese interviewees mentioned centralised management through headquarters and strict decision-making. There is also an awareness of the organisation's hierarchical, bureaucratic and/or paternalistic structure, together with a strong sense of obedience to headquarters. However, some Chinese believed that there is a sense of regional independence and that Chinese agents should be employed. It was highlighted that the organisation ensures that all employees have highly compatible values and are aware of the main customer systems.

\section{Management styles}

A Chinese manager outlined two different culture styles of management for communicating with subordinates (12 h-m):

I think it is some way, you know we Chinese sometimes if I didn't do work MD he can shout at me but we seldom shout at the local staff, you know for me I am ok, it's our way of making us work better but if we do the same thing to local staff they may think something different but to us there is no problem. What I mean is that something of ways of communication between our supervisor and management, he might be using a more straight and tough way and press me to do better, but with local staff we think more about their culture and language and which local staff we accept.

The first is being said is that our management first level we should obey the laws and another is that between the suggestion of our staff between the local and the Chinese and the third thing is that the organisation's headquarters give us the regulation they say the way should be the balances between the suggestions of the local staff and regulation of headquarters, I think everything local wants first and then the second and third the management will balance.

We are more open, our origin for our organisation is a culture to work hard and work more, but to the local we will give them stuff if you want the balances between work and life, you want more leisure time between your family, your family issues we give you a choice but you lose opportunities to be promoted to higher levels because it now depends on you. (Participant 12, Director of finance, Chinese male, 16 years)

The Chinese interviewee shed some light on the communication style of top management in terms of adopting an Eastern (as opposed to Western) management style when communicating with fellow Chinese. However, when relating to members of the Tanzanian culture, the communication changes. According to the interviewee quoted above, the management style encompasses aspects of both Chinese and Tanzanian culture amalgamated into one complex management style.

It seems to be preferable for Chinese management to apply a centralised approach to their Chinese-based headquarter operations, and a decentralised approach to management and supervisory roles, in which the objectives and goals set by higher management levels in other regions are carried out. However, some Chinese think that this systematic approach could create uncertainty in management because managerial roles may vary greatly depending on the subjectivity of the working environments.

With a high standard of discipline in compliance with the Chinese culture, managers have set goals to work towards as performance-based indicators are adopted for incentive purposes. A high level of cultural respect expands further into their international operations. Subsequently the Chinese will adopt separate management systems for their local and Chinese employees in order to accommodate the local cultural aspects of their working environments. Other Chinese employees stated that the overall managerial methods of the private Chinese organisation are compatible with the Tanzanian environment as the organisation uses an international style of management that is intercultural.

\section{Employment}

A top Chinese employee (1 h-m) commented:

If you think about the total amount, it is sixty-five per cent local. Almost all the local people are in the support team. In the sales team, we have three or four people who local staff from here in Tanzania. So in total it is sixty-five per cent ... Now most of the Chinese people are working in sales, and most of the Chinese people stay in the sales team. It is because, for telecommunication, you need education. Unfortunately, the ICT people in Tanzania still need some training for it. (Participant 1, Deputy managing director, Chinese male, 35 years)

The interviewee connects a lack of local employment in the sales team with a lack of education. With regard to the ratio of Chinese to Tanzanian employees in the organisation, all interviewed employees agreed that there were more local Tanzanian than Chinese employees, although the actual numbers given differed slightly between interviewees. Overall, the employees agreed that there was an uneven spread of employees in favour of locals.

A Chinese employee ( $1 \mathrm{~h}-\mathrm{m})$ put the issue of employment opportunities like this:

In our organisation, the employment depends on our business. If the business is going good, we hire more people. In 2007, our business hire many local people from the southern side of Tanzania. We had huge projects and one of those project was in Zambia. Now we have only about a hundred and twenty projects. So the new positions really depend on the business. If 
we find loss in this project, we will need a lot of people to hire. So if we have a new customer coming out, we need a new accounting manager. So that is how new positions come in the organisation. (Participant 1, Deputy managing director, Chinese, male, 35 years)

Obviously, employment opportunities are tightly connected to the volatile business situation in the respective countries, focusing on the demand side of business. Other Chinese employees were convinced that there are broad training opportunities available to all employees and underline the supply side; these opportunities were understood to be extremely skill-based which would grow the organisation into an expansionary position.

\section{Qualification and training}

A Chinese employee (6 h-m) observed:

Let me think, there are two kinds of support I get. Firstly, I get enough materials and resources to do my research and a local internet network where I can search the organisation's internet website to get as many things as I need to carry on with the research. Secondly, I get some training from this research project and when I am doing business, I will have people who have taught me and will eventually support my business. (Participant 6, Pre-sales engineer, Chinese male, 35 years)

This Chinese employee showed his full satisfaction with support and training received from the organisation. In order to increase the levels of qualification, Chinese and Tanzanian employees were offered the opportunity to register for a master's degree in computer science and engineering. The beneficiaries of this offer of qualification and training are most likely to be the less-skilled labour force of Tanzania.

\section{Knowledge-sharing}

A Chinese employee (11 h-m) discussed knowledge-sharing in terms of using the in-house e-database which is accessible to everyone:

We have a very open e-learning platform we can call it an office system where we have e-learning platform which carries all types of knowledge and we have a system ... and you can find any information you want which is related to your work. This is [our organisation] and what we did all the information from different countries and project experience or specific technology training material everything we share it in one database and one platform. Any staff can use their ID and just log in the office platform ... Chinese and local staff are very open in communication and they work together very closely. (Participant 11, Public relations manager, Chinese male, 40 years)

According to some other Chinese interviewees, Tanzanians do not participate in knowledge-sharing. They felt that the organisation is not cross-cultural because of this; however, other interviewees believed that there are good cultural exchanges in the organisation. Information transparency and sharing was also encouraged through weekly meetings with the employees. Chinese employees were convinced that they strive to help local entrepreneurs to gain experience and knowledge through exchange of ideas.

\section{Motivation and incentives}

In the words of a Chinese employee (10 h-m), salaries and promotion are the main triggers for a highly motivated commitment at work:

Motivation of course by increasing the salaries and higher positions for every employee in the organisation, they have to pass, from engineer to project manager and to the FR they have fulfilment responsibility and also maybe to the representative of the office and even to the region office. So they can go and follow the schedule and pass the exam then they can get a promotion. (Participant 10, Product manager, Chinese male, 35 years)

The organisation offers broad training opportunities with governmental support which ensures that sufficient training of new employees occurs, all leading to increased monetary and promotional rewards and performance-related pay, as confirmed by numerous Chinese interviewees. All motivational systems, including the efficiency of management, contribute to the working conditions and atmosphere of the organisation. Chinese interviewees also described the good motivational structures, which are in place such as performance-related pay (bonuses), needsbased incentives and monetary and promotional rewards. In addition, they noted that employees are given 28 days of annual leave.

\section{Working conditions and atmosphere}

A Chinese employee ( $2 \mathrm{~h}-\mathrm{m})$ explained how he socialises during work time and after work:

I stay most of the time with Chinese people. Work time, I spend my work time with the locals and Chinese people. And in my spent time, I stay with my Chinese colleagues, because we are new in this area. Most of us are single even though we are married, but our families are in China, but we stay together. (Participant 2, Product manager, Chinese male, 40 years)

This employee reflects on his family ties and the loss of his family members owing to his appointment to work in Tanzania. The organisation's working conditions and environment are described by some Chinese interviewees as being like a family, which creates a pleasant atmosphere with a strong cross-cultural aspect. Tanzanian employees also appear to like working in the organisation.

\section{Environment, community, government and trade unions}

A Chinese employee (6 h-e) stated:

Two months ago, Mr Chi the founder came to Tanzania and we came Tanzania's private organisation. There is also a lot of companies that come from China and move to Tanzania. Therefore, I think China and Tanzania is developing a very good relationship and also there are a lot of business opportunities here in Tanzania, and it is for the good of two countries. And it is good for me to work here. (Participant 6, Pre-sales manager, Chinese male, 35 years)

Likewise, other Chinese employees believe that China and Tanzania have a very good international partnership. The Chinese see many opportunities because Tanzania's foreign 
policy is very open to foreigners and the country provides a safe environment for its visitors. As a result, there are many Chinese companies in Tanzania, and it is seen as a place with many business opportunities. It was emphasised that the relationship with the Tanzanian government is good, as they have had a history of strong, positive relations. Employees mentioned that only 30 years ago, China was almost at the same level of development as Tanzania. Therefore, the Chinese find such an environment familiar. Currently, the Chinese perceive only infrastructural problems in Tanzania in that the country's technology is seen as inferior to China's. In turn this leads to poor networking within the country. There were no clear views expressed by Chinese interviewees on the existence and function of Tanzanian trade unions, or how unions might affect the work in the organisation.

The Chinese organisation has created 200 local jobs and donated 3000 sports uniforms to schools in the community; corporate social responsibility is contributing to a sustainable environment. However, widespread corruption could impact on Chinese activities in Tanzania.

The Chinese interviewees observed that Chinese people are not aware of many issues affecting Africa, especially such factors as disease and war. However, these difficulties can be outweighed by the beauty of many African locations such as Lake Victoria and Zanzibar.

\section{How could perceptions and conflicting intercultural collaboration be improved?}

Both Tanzanian and Chinese employees in the Chinese organisation shared ideas and opinions regarding ways in which the conflicting intercultural collaboration could improve.

Tanzanian ideas for future collaboration with the Chinese included suggestions that Chinese employees should improve their knowledge regarding intercultural lifestyles:

- use English and Swahili language to make friends

- collect information about Tanzanian history of the last 100 years

- know Tanzanian lifestyle, tribal culture, dressing and food habits

- respect Tanzanians

- recognise that most Tanzanians believe in God

- take care of nature.

In the perception of the Chinese employees, Tanzanians should learn to:

- understand Chinese culture, basic language and history

- acknowledge that Chinese feel pressure

- notice how Chinese save their salaries

- accept that Chinese do not believe in God, have no churches

- appreciate that Chinese are helpful

- strive for sound planning, goal achievement, efficiency

- keep to deadlines
- follow the truth and be honest

- respect Han culture's principles: fast, hardworking, high technology, work for $16 \mathrm{~h}$ a day

- see 'Chinese culture as a big ball that spins and absorbs from all other cultures, mixing them with Chinese culture until it is like one Chinese culture'.

Interestingly, both, Tanzanian and Chinese employees provided future-directed ideas about what members of the 'other' group of employees could do to increase positive and constructive intercultural collaboration. However, neither group made reference to what they could themselves do to improve intercultural collaboration. All participants felt that their reference group was behaving in the correct manner.

\section{Ethical considerations}

The research study followed clearly defined research ethics. Informed consent was provided in writing by the organisation, as well as orally by all the voluntarily participating interviewees. Participants were assured of research ethics, including anonymity, confidentiality and the freedom to withdraw at any time during the research process. Ethical approval for the research was provided by Rhodes University in Grahamstown, South Africa.

\section{Discussion}

Findings support the view of Kikwete (Majani, 2013) that Chinese and Tanzanian employees see their collaboration as a mutual and beneficial business collaboration which dates back in the history (as described in Curtis, 2015) and is built on strong intercultural interaction within the south-south trading collaboration (see Bräutigam, 2009). However, both Chinese and Tanzanian employees see the collaboration as challenging to a certain degree (as emphasised in Bräutigam, 2009). The findings of the current study support Bräutigam's viewpoint (2009) that Chinese employees have a certain understanding of Tanzanian employees and of the structures and challenges they experience in terms of intercultural collaboration, while aiming to build self-reliance (Bräutigam, 2009).

The findings show that managing people in African countries requires multifaceted knowledge (Jackson, 2004; Luiz, 2006) regarding cultural and value concepts of work, (King et al., 2007), references to Tanzanian philosophies of management such as Ubuntu (Luchien \& Honorine, 2005), as well as the understanding of recent changes at different societal and organisational levels (Hart, 2002). Culturespecific understanding is needed to cooperate effectively and to manage challenges around administrative organisation, political instability, personal security, lack of business confidence, transparency and difficult labour relations, as described by Humphreys and Bates (2005).

Findings of our study support findings of previous research and highlight that challenges occur in intercultural collaboration regarding strategy, structure and decision- 
making, management styles, ratio of Chinese to Tanzanian employees, qualification and training, employment opportunities, knowledge-sharing, motivation and incentives, working conditions and atmosphere, as well as challenges in terms of the environment, the community, government and trade unions. This study also shows that Tanzanian employees struggle to gain knowledge from the Chinese employees (as noted in Ado et al., 2016).

The research emphasises that an empathetic approach in intercultural collaboration is needed from all parties on a micro level, as well as on a systemic organisational management level (Graen et al., 2004) to ensure successful and effective collaboration in which all parties act on an equal footing (Graen et al., 2004). This study shows further that intercultural collaboration is influenced by the national culture surrounding the organisation, by the organisational culture itself and by the perceptions of individuals acting within the systems (Trompenaars \& Asser, 2010).

In particular, the perceptions of Chinese and Tanzanian employees on how the intercultural collaboration can be improved shows that participants in this research are influenced by their cultural background in terms of their cognition, their attitudes and their behaviour and actions (see also Mayer, 2008; Zait \& Spalanzani, 2009). Participants show solidarity with employees who belong to their own cultural group (Rosinski, 2011), while expecting members of the other cultural group to move towards improving the intercultural collaboration and relationships. This shows that intercultural collaboration within the organisation can still be improved, towards a more equal and understanding work partnership. As suggested in previous research, African and Chinese philosophies could support management practices and bridge cultural differences (Nyambegera et al., 2016). This is supported by the current findings, in which members of both groups suggest learning about the other group's philosophies to broaden perceptions of 'the other'.

This study finally highlights the need for more research with regard to Chinese-Tanzanian collaborations and thereby supports the conclusions of Mayer (2013) and Mayer and Louw (2011).

\section{Limitations}

This research study is limited to a single case study and only takes into account the 16 interviewees who agreed to participate in the project voluntarily. The study is, therefore, not generalisable in quantitative terms, but contributes to an increase of qualitative, in-depth knowledge on intercultural work relationships and perceptions.

\section{Implications for theory and practice}

The findings show that intercultural collaboration is a challenge for both Chinese and Tanzanian employees in the selected private Chinese organisation. Referring to the main research aim, it was found that Chinese employees share a mostly positive view of their organisation, while Tanzanians are generally more critical of the organisation.

Challenging intercultural collaboration is perceived in the contexts of strategy, structure and decision-making, management styles, employment, qualification and training, knowledge-sharing, motivation and incentives, working conditions and atmosphere, as well as the environment, the community, government and trade unions. These areas of perceived cultural differences and challenges provide indepth information and at the same can be regarded as guidelines for theoretical and practical implications.

Future human resource management research should, if possible, focus on intercultural collaboration by using a positive psychology or positive organisational perspective, focusing on what works best in Chinese-Tanzanian collaboration in different organisational contexts and industry sectors. The best approach would be to use mixed method studies for further investigation, taking intercultural collaboration on all levels into account.

On a practical level, employees in Chinese organisations should be trained in the basics of intercultural collaboration to improve the understanding of the self and the other within the organisation, to reflect on stereotypes and prejudices and to improve the understanding of thought styles, experience, knowledge and basic cultural values and concepts. The human resource officer within the organisation should make use of cultural diversity programmes in the workplace to enhance mutual cultural awareness and understanding among employees. Furthermore, Chinese organisations could be more open to making use of intercultural training with external facilitators and consultancy to assist changing the perceptions of employees constructively and build effective and sustainable intercultural collaborations within the organisation. The perceptions of the employees and their practical skills and abilities to deal with intercultural challenges and collaboration constructively, could also be achieved through Organisational Development Interventions, such as team building exercises, quality circles and leadership consultancy.

The implementation of interventions, training and programmes in opening up the organisational culture can be achieved by using both bottom-up and top-down approaches, supported by the Chinese leadership of the organisation. Chinese leaders need to increase their awareness in the context of intercultural collaboration and implement strategies which are based on an intercultural collaboration. Besides enhancing intercultural collaboration through human resources management, strategic and systemic management practices also need to be used to create structures of equal opportunities, embracing diversity. These practical practices might impact positively on the working conditions and atmosphere, qualification and training, knowledge-sharing and motivation of employees. 


\section{Acknowledgements}

This work is based on the research supported in part by a research grant from Rhodes University, Grahamstown, South Africa.

\section{Competing interests}

The authors declare that they have no financial or personal relationships that may have inappropriately influenced them in writing this article.

\section{Authors' contributions}

C-H.M. and C.M.B. conducted the field research and analysed the data. All three authors discussed and interpreted the findings and wrote up the research article. L.L. is the leader of the overall project on Chinese organisations in sub-Saharan Africa: New dynamics, new insights.

\section{References}

Ado, A., Su, Z., \& Wanjiru, R. (2016). Learning and knowledge transfer in Africa-China JVs: Interplay between informalities, culture, and social capital. Journal of International Management. Retrieved December 23, 2016, from http://www. sciencedirect.com/science/article/pii/S107542531630357X

African Economic Outlook. (2014). Trade policies and regional integration in Africa. Retrieved August 11, 2016, from http://www.africaneconomicoutlook.org/ fileadmin/uploads/aeo/2014/PDF/Chapter_PDF/03_Chapter3_AEO2014_EN. light.pdf

Bräutigam, D. (2009). The Dragon's gift: The real story of China in Africa. London, UK: Oxford University Press.

Collis, J., \& Hussey, R. (2003). Business research: A practical guide for undergraduate and postgraduate students. (2nd edn.). New York: Palgrave Macmillan.

Creswell, J.W. (2003). Research design: Qualitative, quantitative and mixed methods approaches. (2nd edn.). London, UK: Sage.

Curtis, A. (2015, March 11). China's long history in Africa. Retrieved August 17, 2016 from http://newafricanmagazine.com/chinas-long-history-africa/

De Klerk, S., \& Kroon, J. (2007). Networking in South African businesses. Management Decision, 45(1), 83-103. https://doi.org/10.1108/00251740710718980

George, G., Khayesi, J.N.O., \& Haas, M.R.T. (2016). Bringing Africa in: Promising directions for management research. Academy of Management Journal, 59(2), 377-393. https://doi.org/10.5465/amj.2016.4002

Giese, K. (2013). Same-same but different: Chinese traders perspectives on African labor. The China Journal, 69. 134-153. https://doi.org/10.1086/668841

Graen, G.B., Hui, C., \& Gu, Q.L. (2004). A new approach to intercultural cooperation. LMX Leadership, 225-246. Retrieved n.d., from https://www.researchgate.net/ profile/George_Graen2/publication/292729391_A_NEW_APPROACH_TO INTERCULTURAL_COOPERATION/links/56b0dde408ae-9c1968b9̄7809.pdf

Gummesson, D.E. (2000). Qualitative methods in management research. (2nd edn.). Thousand Oaks, CA: Sage.

Harris, H., Brewster, C., \& Sparrow, P. (2006). International human resource management. (3rd edn.). London, UK: CIPD.

Hart, G.P. (2002). Disabling globalization: Places of power in post-apartheid South Africa. Berkeley, CA: University of California Press.

Hinds, P., Liu, L., \& Lyon, J. (2011). Putting the global in global work: An intercultural lens on the practice of cross-national collaboration. Academy of Management Annals, 5(1), 135-188. https://doi.org/10.1080/19416520.2011.586108

Humphreys, M., \& Bates, R. (2005). Political institutions and economic policies: Lessons from Africa. British Journal of Political Science, 35, 403-428. https://doi. org/10.1017/S0007123405000232

Jackson, T. (2004). Management and change in Africa. A cross-cultural perspective. London, UK: Routledge.
Kamoche, K. (2002). Introduction: Human resource management in Africa International Journal of Human Resource Management, 13(7), 993-997. https:// doi.org/10.1080/09585190210131258

Kamoche, K.N., Debra, Y.A., Horwitz, F.M., \& Muuka, G.N. (2004). Managing human resources in Africa. London, UK: Routledge.

King, N., Kruger, N., \& Pretorius, J. (2007). Knowledge management in a multicultura environment: A South African perspective. Aslib Proceedings, 59(3), 285-299. https://doi.org/10.1108/00012530710752061

Koehn, P.H. (2007). Peaceful and sustainable development? Middle-management entrepreneurship and transnational competence in China. East Asia, 24(3) 251-263. https://doi.org/10.1007/s12140-007-9017-9

Luchien, K., \& Honorine, I. (2005). Ubuntu as a key African management concept: Contextual background and practical insights for knowledge application. Journal of Managerial Psychology, 20(7), 607-620. https://doi.org/10.1108/026839 40510623416

Luiz, J. (2006). Managing business in Africa: Practical management theory for an emerging market. Cape Town, SA: Oxford University Press.

Majani, F. (2013, October 13). China drops anchor in Tanzania. Retrieved August 16, 2017, from http://mg.co.za/article/2013-10-04-00-china-drops-anchor-intanzania

Matondo, J.P.M. (2012). Cross-cultural values comparison between Chinese and SubSaharan Africans. International Journal of Business and Social Sciences, 3(11), 38-52.

Mayer, C.-H. (2008). Managing conflict across cultures, values and identities. A case study in the South African automotive industry. Marburg, Germany: Tectum.

Mayer, C.-H. (2011). The meaning of sense of coherence in transcultural management. Münster, Germany: Waxmann

Mayer, C.-H. (2013). China in Tanzania. In Presentation at Symposium China in Africa. Implications for Management, Implications for Change, Rhodes University, Grahamstown, South Africa, 31 October 2013-01 November 2013, n.p.

Mayer, C.-H., \& Boness, C.M. (2011). Culture and conflict in urban Tanzania: Professionals' voices in educational organizations. African Journal on Conflict Resolution, 11(2), 59-83. https://doi.org/10.4314/ajcr.v11i2.69833

Mayer, C.-H., \& Louw, L. (2011). Managerial challenges in South Africa. European Business Review, 23(6), 572-591. https://doi.org/10.1108/09555341111175417

Mayer, C.-H., \& Louw, L. (2012). Managing cross-cultural conflicts in organizations, International Journals of Cross Cultural Management, 12(1), 3-8. https://doi. org/10.1177/1470595811413104

Mayer, C.-H., Boness, C.M., Louw, L. \& Louw, M.J. (2016). Intra- and inter-group perceptions of Chinese and Tanzanian employees in intercultural cooperation. Proceedings of the 28th Annual Conference of the Southern African Institute of Management Scientists. Retrieved August 24, 2017, from http://www.up.ac.za/ media/shared/643/ZP_Files/2016/Papers/hrl18_full.zp97856.pdf

Nyambegera, S.M., Kamoche, K., \& Siebers, L.Q. (2016). Integrating Chinese and African culture into human resource management practice to enhance employee job satisfaction. Journal of Language, Technology and Entrepreneurship in Africa, $7(2), 118-139$.

Pillay, R. (2008). Managerial competencies of hospital managers in South Africa: A survey of managers in the public and private sectors. Human Resources for Health, 6(4), 1-7.

Rosinski, P. (2011). Global coaching for organizational development. International Journal of Coaching in Organizations, 8(2), 49-66.

Sycara, K., Gelfand, M., \& Abbe, A. (2013). Models for intercultural collaboration and negotiation. Dordrecht, Netherlands: Springer.

Tanzanian-Zambia Railway Authority. (2017). Tazara. Retrieved August 16, from http:// tazarasite.com/?page_id=131

Terre Blanche, M., Durrheim, K., \& Kelly, K. (2006). First steps in qualitative data analysis. In M. Terre Blanche, K. Durrheim, \& D. Painter (Eds.), Research in practice. Applied methods for the social sciences (pp. 321-344). Cape Town, South Africa: University of Cape Town Press.

Trompenaars, F., \& Asser, M.N. (2010). The global M and A Tango: Cross-cultural dimensions of mergers and acquisitions. New York: McGraw-Hill.

van der Nest, D. (2004). The impact of black economic empowerment on the management of small companies in South Africa. Retrieved August 16, 2017, from https://ujdigispace.uj.ac.za/bitstream/handle/10210/319/ImpactofBEEonthe MngofSMEinSouthAfrica.pdf?sequence $=1$

Yin, R.K. (2009). Case study research: Design and methods. (2nd edn.). London, UK: Sage.

Zait, D., \& Spalanzani, A. (2009). La recherche en management et en economie [Research in management and economics]. Reperes epistemologiques et methodologiques. Paris: L'Harmattan. 